\begin{tabular}{|l|l|l||}
\hline \multicolumn{2}{|c|}{ PublisherInfo } \\
\hline \hline PublisherName & $:$ & BioMed Central \\
\hline \hline PublisherLocation & $:$ & London \\
\hline \hline PublisherImprintName & $:$ & BioMed Central \\
\hline \hline
\end{tabular}

\title{
Homologous recombination in animal mitochondria
}

\begin{tabular}{|l|l|l||}
\hline \multicolumn{2}{|c||}{ ArticleInfo } \\
\hline \hline ArticleID & $:$ & 3884 \\
\hline \hline ArticleDOI & $:$ & $10.1186 /$ gb-2001-2-10-reports0034 \\
\hline \hline ArticleCitationID & $:$ & reports0034 \\
\hline \hline ArticleSequenceNumber & $:$ & 16 \\
\hline \hline ArticleCategory & $:$ & Paper report \\
\hline ArticleFirstPage & $:$ & 1 \\
\hline \hline ArticleLastPage & $:$ & 5 \\
\hline \hline & & RegistrationDate : 2001-8-3 \\
ArticleHistory & $:$ & Received \\
\hline \hline ArticleCopyright & $:$ & BioMed Central Ltd2001-8-3 \\
\hline \hline ArticleGrants & $:$ & \\
\hline \hline ArticleContext & $:$ & 13059221010 \\
\hline \hline
\end{tabular}




\section{James Cotton}

\section{Abstract}

An unusual genetic system has allowed recombination to be recognized in an animal mitochondrial genome.

\section{Significance and context}

Maternal transmission of mitochondria is the rule-of-thumb across all eukaryotes, but important exceptions have long been known. Plants, for example, show the whole range of mitochondrial inheritance, from fully maternal through biparental to paternal inheritance. Closer to home, paternal leakage has been reported in a fungus, in Drosophila and even in mice, and a particularly exotic pattern of inheritance has been demonstrated in mussels. The ruling paradigm of purely maternal inheritance came hand-in-hand with the assumption that mitochondrial DNA (mtDNA) did not recombine, but there is now direct evidence of homologous recombination in plant, fungus and protist mtDNA. The belief that animal mtDNA does not undergo homologous recombination has proved harder to shake.

This is rather surprising, as this paradigm is based on indirect evidence and is challenged by a growing body of data. The original observation that paternal mitochondria do not penetrate the egg is now known to be in error, with paternal organelles persisting for several hours after fertilization. It is also known that mammalian mitochondria contain the necessary enzymatic machinery for homologous recombination, and mitochondrial fusion is well known in Drosophila. Non-homologous recombination (unequal crossing-over) has been held responsible for variation in the number of tandem repeats in a number of animal mitochondrial genomes, and has been directly observed in a nematode. Two recent population studies have also suggested that recombination has occurred in human mtDNA.

With all this evidence, it would seem likely that homologous recombination does occur in animal mitochondria, but the publication of human population studies last year provoked considerable debate, emphasizing that there is much interest in whether animal mtDNA does show homologous recombination, and considerable skepticism. Many authors will no doubt remain skeptical, despite the results of this paper, in which Ladoukakis and Zouros have exploited the unusual genetic system of the mussel to uncover direct evidence for homologous recombination within animal mitochondria. 


\section{Key results}

The unusual biparental inheritance of mitochondria in mussels of the families Unionidea and Mytilidaehas been known for about a decade, and is an interesting exception to the otherwise universal rule of maternal inheritance for animal mtDNA. Normally, female (F) and male (M) mitochondrial sequences differ by $20 \%$ - too great an amount to expect to observe homologous recombination. Luckily, a quirk of the Mytilus system allows a unique opportunity to observe mtDNA recombination in action. Occasionally, $\mathrm{F}$ genomes become 'masculinized', invading the $\mathrm{M}$ transmission route in sperm (see Figure 1). These $\mathrm{M}^{\mathrm{F}}$ genomes can now diverge from the ancestral $\mathrm{F}$ form, so we can find in a single cell mitochondrial genomes that have sufficient sequence difference to allow homologous recombination to be detected, but not so much that recombination would be suppressed.

The authors report a number of sequences from the gene for cytochrome oxidase subunit III, where it seems clear that short pieces of DNA have been exchanged between $F$ and $M^{F} m t D N A$. Out of thirteen different sequences, six appear to be recombinants between the two most common alleles in the population, with recombinant fragments ranging in length from 24 bases to over 200 .

Figure 1 The unusual mitochondrial inheritance sy

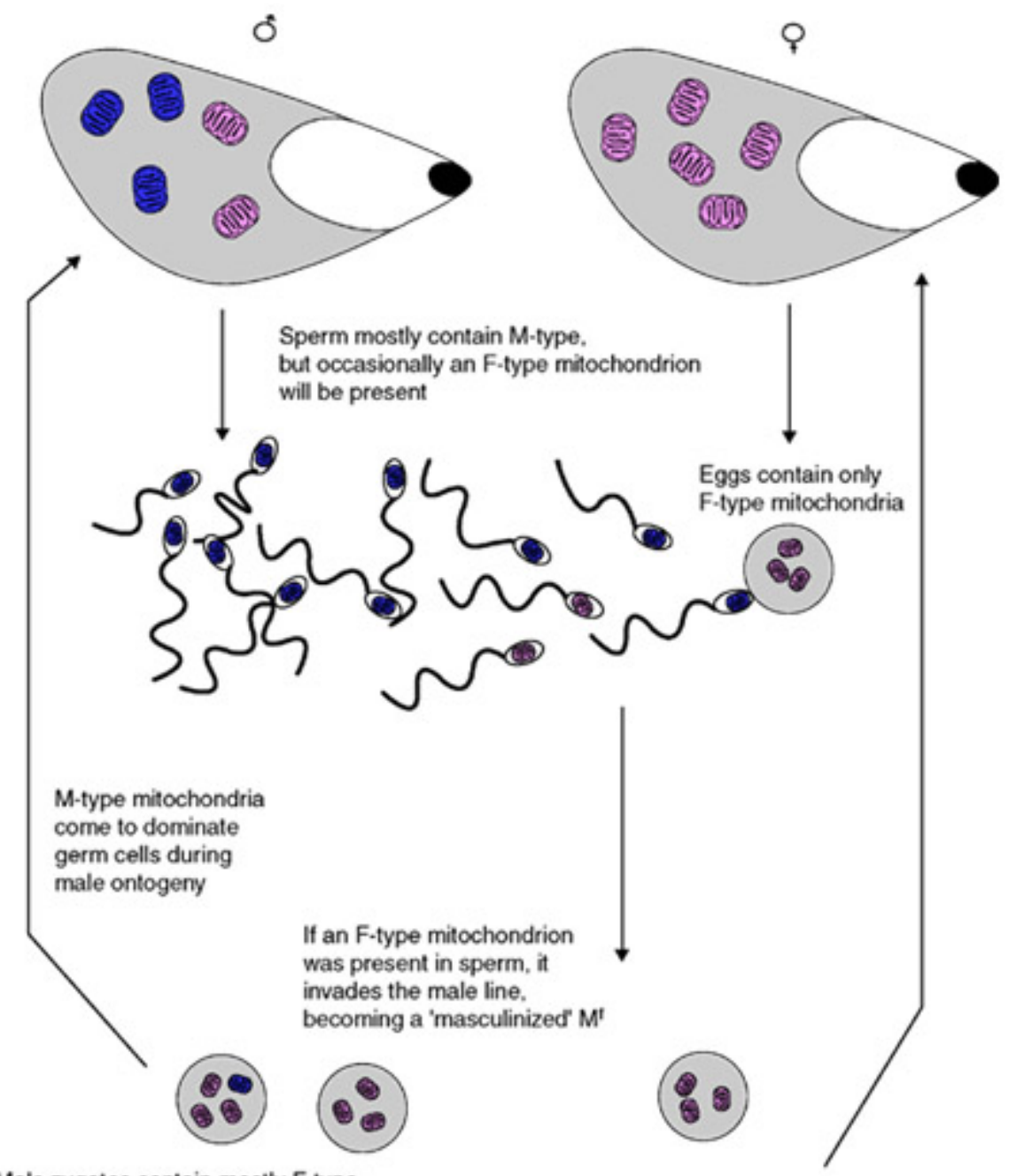

Male zygotes contain mostly F-type

(as the egg contains many more mitochondria),

but some M-type mitochondria persist 


\title{
Methodological innovations
}

The molecular techniques used in this work are standard, but I was impressed by the thoroughness with which Ladoukakis and Zouros ensured that their results were due to genuine in vivo recombination and not to 'in vitro recombination' in the formation of PCR chimeras.

\section{Conclusions}

The take-home message is simple - homologous recombination is certainly occurring in the unusual genetic system of Mytilus mitochondria. This makes it likely that similar recombination is also occurring in mitochondria in other organisms, unless it can be demonstrated that recombination is an integral part of the mussel's aberrant inheritance system - but there is no obvious reason why this should be the case.

\section{Reporter's comments}

The fairly incontrovertible evidence that recombination has been occurring in Mytilus would just be an interesting aside were it not for the fact that it opens up the possibility that recombination occurs more widely between animal mtDNAs. We would expect it to be much more difficult to detect in other systems, where the divergence between recombinants is likely to be small, but it could nevertheless have a significant effect on the evolutionary dynamics of mitochondrial DNA. It would, for example, make the history of mtDNA haplotypes a network rather than a tree, calling into question the results of studies that have attempted to study the origin of humans on the basis of mitochondrial data; it is simply meaningless to discuss the timing of particular branching events on a phylogenetic tree if the pattern of inheritance is not, in fact, tree-like. Mitochondrial recombination is not all bad news, however. As has been pointed out previously, it may make unraveling the history of mtDNA much more difficult, but it also makes mtDNA a more typical genetic marker, and a more accurate reflection of the true history of the genome as a whole.

Ladoukakis and Zouros also present an excellent example of how the choice of an appropriate (and in this case, rather unusual) model organism can be of crucial importance. Working with Mytilus has enabled them to establish something that has escaped workers on more mainstream genetic models.

\section{Table of links}

\author{
Molecular Biology and Evolution
}




\section{References}

1. Ladoukakis ED, Zouros E: Direct evidence for homologous recombination in mussel (Mytilus galloprovincialis) mitochondrial DNA. Mol Biol Evol. 2001, 18: 1168-1175. 0737-4038

This PDF file was created after publication. 